\title{
Evaluation of a Curriculum
}

\author{
Yuxia Yang \\ English Department of Social Sciences and Humanities \\ Xi' an University of Technology \\ Xi'an, China 710048
}

\begin{abstract}
Evaluation is an on-going and evolutionary process in the development of a curriculum in which it may encompass different people in the different periods like audience, participants or observers. Strictly speaking evaluation cannot only be thought as tests and it is broader than tests, assessment or measurement. In one curriculum, evaluation should include formative, illuminative and summative evaluation by which curriculum can be run smoothly and healthily.
\end{abstract}

Keywords-evaluation; curriculum; formative evaluation; illuminative evaluation; summative evaluation

\section{INTRODUCTION}

The process of a curriculum is never-ending process: Once a curriculum has finished, a great number of questions still need to be taken into account. Is this curriculum suitable for students' needs? Does the curriculum meet teaching objectives? (Richards, 2001:286)

\section{CONTEXT AND RELATED CONCEPTS}

In China, it is a universal belief that evaluation is equal to testing including majority of our teachers. Such as, unit tests, final exams, and entrance exams. In fact, testing is the only one part of evaluation in the programme. As Brown points out, "Testing only refers to procedures that are based on tests." (Brown, 1995: 219) According to testing, it is not comprehensive to judge how well students have learned and why some students cannot pass exams, etc. however, some people may consider evaluation as assessment or measurement. However, these three are different concepts. It is necessary to make a clear clarification about what they are. "Measurement not only includes testing, but also other types of measurements that result in quantitative data such as attendance, records, questionnaires, teachers rating of students (or student ratings of teachers) and so forth."(Brown, 1995:219) "Assessment is the more inclusive term: it refers to the general processing of monitoring or keeping tracking of the learners' progress. (Hedge, 2001:376)

In fact, evaluation is much more boarder term than assessment or measurement. In Nunan's book "No curriculum model would be complete without an evaluation component....Evaluation, on the hand, is a wider term, entailing assessment, but including other processes as well. These additional processes are designed to assist us in interpreting and acting on the results of our assessment....Evaluation, then, is not simply a process of obtain information, it is also a decision-making process." (Nunan, 1991:118)

From the above definitions, it is clear that evaluation indeed plays a vital role in the curriculum development. Evaluation is an intrinsic part in teaching and learning. A good evaluation not only provides rich information for teachers to use in the classroom practice such as planning courses, modification teaching methods, management of learning tasks and students' learning process but also helps evaluators make decisions about which part of the programme should be modified so as to improve effectiveness of the programme. Consequently, it is quite necessary for educational authorities and teachers in China to make a clear and complete concept about evaluation and think about how we should evaluate our programme comprehensively.

\section{WhO GET INVOLVED IN EVALUATION?}

\section{A. Audience in the evaluation}

Based on Richards' view, there are two types of people who are involved in evaluation. One is audience in the process of evaluation. This type of people is interested in getting information related to evaluation. For instance, students' parents are willing to know what their child has learned at the end of one term. Curriculum developers might want to know whether the design of this course is appropriate. In addition, Richards emphasizes that "In planning an evaluation it is important to identify who the different audiences are what kind of information they are most interested in." (Richards, 2001:294)

At the beginning of publishing new textbooks, textbook publishers might be mainly concerned with information about whether this textbook can still meet students' needs now. In the process of teaching, teachers might be eager to acquire information about how about their teaching methods and whether this method can achieve teaching aims. Some students might want to know why I can not do better comparing with other students and what I have learned in this term. In China, National Ministry of Education is the head who is chiefly responsible for collecting all of information from the local education departments. In a word, different types of audience need different information. Therefore, it is wise to distinguish who they are and what kind of information they are looking for. 


\section{B. Participants in the evaluation}

Evaluation is a quite complex and meaningful process during the development of curriculum. Based on Nunan's (1991) views "who" "what" "how" "why" are included in evaluation where "who" are involved in evaluation is the first element. In light of Richards' book, there are two types of participants who typically take part in evaluation. The first one is insiders. These are people who are directly involved in and have a close relationship with the development and implementation of the curriculum. Such as, teachers, students themselves, head teachers. For example, head teachers are in charge of monitoring teachers' work including observation, seminar.

Students are key participants in evaluation of the programme. They can provide important information about whether this teaching method is useful or not and what kind of activities they are interested in. However, in China students' involvement in evaluation is always neglected because most schools still consider students as receivers of evaluation not evaluators. They are hoping students to pay much more attention to their studies rather than to take part in other activities like evaluation.

In fact, insiders play a significant role in the process of evaluation. Generally speaking, insiders have direct experiences of the situation; in particular, they themselves are doing what evaluators want to know. As a consequence, they can provide evaluators adequate information with their particular understandings and perceptions for decisionmaking. For example, teachers are able to explain and offer different and relevant classroom phenomena with their experiences obtained over long periods of teaching. Students get involved in programme from the beginning to the end to ask themselves such kind of questions. Why I cannot achieve this goal? How can I memorize vocabulary effectively? To some extent, these questions might be regarded as a kind of evaluation which is helpful for teachers to master students' condition in the programme.

Another type of participants in the process of evaluation is outsiders. These are people who do not directly get involved in the programme. For example, programme administers such as experts and consultants may play a role. They intend to complement and illustrate some phenomena about to what extent this syllabus is not useful for lower level students and how to promote students motivation in language learning.

In China, National Ministry of Education analyze information acquired from local education departments and play a crucial role in making decisions about what kind of syllabus should be applied this year. What kind of goals should be achieved during this period of time? The personnel including education expertise, administers in local education and some experienced teachers are concerned with course design and compiling textbooks according to guidelines and principles of National Ministry of Education.

\section{What ProducES AND/OR PROCESSES EXACTLY Might THEY BE INTERESTED IN EVALUATING?}

Based on Richards' book, he indicates that "the scope of evaluation has moved from a concern with test results to the need to collect information and make judgements about all aspects of curriculum, from planning to implement." (Hewings and Dudley-Evans, 1996 in Richards book 2001:287) In other words, curriculum design, syllabus, programme content, classroom processes, material, teachers, and students should be included in the process of evaluation.

From insiders' view, teachers are more interested in teaching materials, methods they used, students' learning process. They evaluate whether the materials and methodology can achieve the preset objectives and whether students can master what they are teaching. About outsiders, such as educational authorities, they usually focus on the evaluation of course design, syllabus, and programme content. Whether this content is useful for improving students' listening, whether the syllabus can meet their preset goals and whether the design of this course is suitable for high level students. Not only students' parents but also teachers are likely to evaluate what students' achievements are and how successful the teacher is by the scores of tests. Educational administers do not want to emphasize too much on process of the programme. They merely want to know how many students meet their preset objectives by the results of students' marks. According to this aspect, we can find both insiders and outsiders in China are interested in evaluating the product rather than the process.

Because we do lose sight of the importance of evaluating the process in the programme, sometimes we as teachers do not make sure why our teaching failed, we really do not discern what students needs. For this reason, we are suggested "it is important to be sure when we mention the need to evaluate our language teaching methods, our materials, our effectiveness as teachers and so on, that we actually know what it is we are evaluating. How materials are presented to learners, the types of learning tasks used, and the way that we design our courses, all form different aspects of our work as teachers."'(Rea-Dickins and Germaine, 1992:5)

\section{Why Might They Want to Do This? To What Purpose Might They Put THE FINDINGS?}

The nature of evaluation is to collect relevant information about curriculum systematically in order to assess its effectiveness and promote its improvement. According to Richards' (2001) statement, there are three different purposes about evaluation including formative, illuminative and summative evaluation.

\section{A. Formative evaluation}

Formative evaluation may happen during the process of curriculum development, which aims to collect and analyze information for improving the effectiveness of a curriculum. In formative evaluation, students and teachers should be involved in this activity because both of them experience the process of the programme. They may have a clear idea what 
the programme is. For teachers, they may expect to know whether the methodology he or she is using is appropriate or not. Whether students can master what they have learned today. Whether they are interested in the programme and how to promote their interest or build their self-confidence in listening? Some students may raise such questions unconsciously. How can I learn this effectively? Why I do not use this programme? Clearly, formative evaluation is not only indispensable component in teaching process but also a meaningful activity for improving teaching quality.

The main tasks of formative evaluation are to evaluate students' daily studies and let teachers modify their teaching methods. To a certain degree, formative evaluation can encourage students to learn efficiently and help them master their learning process and achieve the unity of teaching and learning. In this case, systematic formative evaluation really does have a good effect on improvement of the programme in that it helps decision makers have a deeper understanding of internal and external reasons behind the practice, which can lead to success of the programme.

\section{B. Illuminative evaluation}

The second type of evaluation can be regarded as illuminative evaluation. "This refers to evaluation that seeks to find out how different aspects of the programme work or are being implemented. It seeks to provide a deeper understanding of the process of teaching and learning that occur in the programme, without necessarily seeking to change the curse in any way as a result."(Richards, 2001:289) This evaluation may try to answer these questions in the process of the programme. How does this teacher carry out the presentation of past perfect tense? What kind of reading strategy is more appropriate for intermediate students? Does the teacher have a clear introduction about the activities? Through answering these questions, teachers have a clear understanding about what students' perceptions of the course are. Whether students are interested in this method or not? What they most like to do in the class?

Classroom observation or teachers meetings, classroom action research can be regarded as illuminative evaluation. Among them, observation is one of commonly used methods. "Evaluation, on the other hand, means that someone is placing value on some behaviour, the evaluator is trying to decide how good the teacher is, or how well the learners are processing."(Tanner \& Green 96:11) In this way, observation does not necessarily mean watch to judge whether the lesson is good or not, but rather to describe what is happening in class and what is not.

In the book of Evaluation (1992), illuminative evaluation is described as an awareness-raising activity. Definitely, it is a kind of conscious realization in teaching process, which does good to have complete understandings about what students do and how they make sense of their lessons and what teachers should make improvement in the programme.

\section{Summative evaluation}

In Richards' book (2001), the third type of evaluation is summative evaluation that most teachers and programme administers are familiar with. It refers to evaluation of effectiveness, efficiency or acceptability of the programme at the end of it. Summative evaluation is a relatively common way to provide information about whether this programme can meet the objectives of syllabus. Such evaluation may involve testing, measurement, and analysis of statistics, which may bring about modification of the programme, changing materials and methods even dismissal of teachers to some degree.

Based on Hedge description (2001), summative evaluation can review the whole process at the end of the course to point out elements for improvement. But, most of people including teachers have a misunderstanding about summative evaluation, which is regarded as tests. Under this circumstance, tests may be regarded as the only means to make judgements how well students learned, how successful teachers teach. In fact, tests cannot provide complete information about the process of teaching and learning.

A healthy programme needs a combination of summative and formative evaluation. Based on the book of Second Language Curriculum, (1989) it says that summative evaluation allows for an overall view of success or failure rather than focuses on the specific details in formative evaluation. And it is a way to encourage students to look back about what has been achieved so that it can give students and teachers' satisfaction and encouragement about teaching and learning. For formative evaluation, it can reach the unity of teaching and learning by getting information from students immediately. Therefore, teaching can be more effective and efficient. In short, Brown says (1995) both formative and summative evaluation may be useful for the curriculum development.

\section{How Would Any Evaluation Procedures Be CARRIED OUT? WHO WOULD BE INVOLVED IN COLLECTING ANY INFORMATION?}

Before knowing how evaluation is carried out, it is necessary to make clear about two concepts: quantitative data and qualitative data. In Brown's book, "Quantitative data are countable bits of information which are usually gathered using measures that produce results in the form of numbers." "Qualitative data consist of more holistic information based on observations that my not readily lead themselves to conversion into quantities or numbers." (Brown, 1995:227)

There are a lot of procedures which can be used by evaluators for collecting information about the programme. Some of evaluators may be likely to use qualitative data and others may prefer to gather quantitative data. As Nunan (1991) suggests that tools and techniques used for evaluation may depend on what kind of tasks you need to take, which is the most significant thing in the process of evaluation. For example, in summative evaluation tests, students' grades and raking will be used as quantitative data, conversely opinion surveys will be adopted at the end of term as qualitative data. Classroom observation, teachers' inquiry, teachers meetings are qualitative data which are usually used in illuminative evaluation. Interviews, parents meetings and diary studies 
that are qualitative data may use in formative evaluation. Unit tests, quizzes and self-rating are quantitative data in formative evaluation.

Tests and quantitative data are the most direct ways to get information so that they are still commonly used by our teachers in the teaching process. As usual, students take assorted tests at different stages. At last, students' scores are important data in that they are usually viewed as the only means to evaluate students' accomplishment, teachers' work, schools' quality, feasibility and usefulness of the coursebooks and so on. In this process, teachers are mainly responsible for collecting the information about the results of every test and then have systematic analyses about these data. Students' parents may be eager to get information, which they want to get the results of tests to make a decision whether their child need some extra help in learning or not.

To some extent, tests are important and essential, but not exclusive. In other circumstances, other means may be equally useful. Chinese educational authorities pay more attention to other aspects of teaching and learning process, such as, students' needs, students' communicative competence? They may analyze some qualitative data based on tests to make adjustments about the programme. Both quantitative data and qualitative data can provide valuable information that is used in programme evaluation. Richards (2001) suggests that quantitative data focus on scientific principles to collect data that are more objective than qualitative data. On the other hand, qualitative data are more holistic and are concerned with details in natural settings for language use and authentic tasks. In his view, both quantitative data and qualitative data are needed for gathering information in language programme. Clearly, both of them have different functions and can be used to complement for each other.

\section{CONCLUSION}

To sum up, evaluation in fact is not a simple issue but rather a complex and comprehensive issue in the development of a curriculum. It may probably be viewed as the never-ending needs analysis, and it constantly needs to refine ideas in the programme to help the programme run more effectively, efficiently and guarantee a healthy curriculum.

\section{REFERENCES}

[1] Brown, J, D, (1995) the Elements of Language Curriculum: A Systematic Approach to Program Development. Boston, Mass.: Heinle \& Heinle.

[2] Hedge, T (2001) Teaching and learning in the language classroom, Oxford: Oxford University Press.

[3] Nunan, D. (1988) the learner-Centred Curriculum: A Study in Second Language Teaching. Cambridge: Cambridge University Press.

[4] Rea-Dickins, P and Germaine, K (1992) Evaluation, Oxford: Oxford University Press.

[5] Richards, J, C (2001) Curriculum Development in Language Teaching. Cambridge, U.K.; New York: Cambridge University Press.

[6] Robert Keith Johnson (1989) The Second language curriculum, Cambridge: Cambridge University Press
[7] Tanner, R \& Green, C (1998) Tasks for teacher education: a reflective approach. Harlow: Addison Wesley / Longman.

[8] YANG Yuxia, lecturer of English Department of Social Sciences and Humanities, Xi' an University of Technology. 